\title{
Cocoa Bean-Extract Mediated Graphene Quantum Dots as Antimicrobial, Anticancer and Plant Growth Regulators
}

\author{
Anooj E.S, Praseetha P. K
}

\begin{abstract}
A facile method has been developed for the first time for the synthesis of graphene quantum dots using The obroma cacao (cocoa seeds) by hydrothermal method. The structure and morphology of ensuring product was characterized by UV, FTIR, X-ray Diffraction (PXRD) and TEM and SAED pattern. Then anti-microbial, anti-oxidant and anti-cancer activities of $T$. cacao mediated graphene quantum dots were analyzed. Further investigations were made on the use of T. cacao mediated graphene quantum dots for growth enhancement in green gram (Vigna radiate). CSE-GQDs (Cocoa seed extract-Graphene quantum dots) showed greatest antimicrobial activity against the Staphylococcus aureus, Pseudomonas aeroginosa, Streptococcus mutans, Salmonella sp, Escherichia coli, Microsporum gypseum, Trichophyton sp. The results of antioxidant activity of the CSE-GQDs evaluated using DPPH scavenging assays indicates that the CSE-GQDs possess a higher scavenging activity. The cytotoxicity studies showed that the synthesized CSE-GQDs exhibited a dose dependent toxicity on human breast cancer (MCF-7) cell lines. The $I_{50}$ value for MCF-7 cells is found to be $31.2 \mu \mathrm{g} / \mathrm{ml}$ of CSE- GQDs, where a $50 \%$ noticed cell death is observed. The germination rate of green gram seeds significantly increased after treatment with higher CSE-GQDs. Our investigations open up the opportunity to use graphene quantum dots as plant growth regulators that can be used in a variety of other food plants for high yield.
\end{abstract}

Keywords- green gram; XRD, SAED, anti-cancer, anti-bacterial, anti-microbial, plant growth regulators

\section{INTRODUCTION}

Over the last two decades, nanotechnology has formed the most promising discipline within science likely to present solutions for the growing challenges in biomedical applications such as drug delivery, therapeutics and diagnostics [1]. Synthesis of metal nanoparticles like Silver, gold, platinum, copper, selenium, quantum dots etc, with a particular shape, size and morphology is an important area of modern research [2]. Graphene quantum dots (GQDS), the zero-dimensional graphene nanoparticles with unique

Revised Manuscript Received on October 25, 2019.

Anooj E.S, Department of Nanotechnology, Noorul Islam Centre for Higher Education, Kumaracoil, Kanya kumari District. Tamilnadu, India

Praseetha P. K* , Department of Nanotechnology , Noorul Islam Centre for Higher Education, Kumaracoil, Thuckalay, Corresponding Email: crkpkp@gmail.com properties such as biocompatibility and photoluminescence have attracted remarkable interest in the field of nano-science [3]. Due to their excellent optical and electrical property, low-toxicity, and non-pollution, this nano-material is promising to replace semi-conductor quantum dots (SQDs) in solar cells, drug delivery, photocatalysts [4].

So far, various methods have been utilized to prepare GQDs. GQDs are commonly produced by methods involving top down and bottom-up approaches, which are demanding in terms of time, energy and materials. The bottom up approach involves chemistry solutions [5-6], carbonization, a complex procedure which include use of exotic precursors and/or high quantities of organic solvents, which lead to large volume generation of waste [7]. However, GQDs produced by bottom-up procedures are of low standards and exhibit poor stability. On the other hand, the top-down approach, reported techniques involving hydrothermal cutting [8], electrochemical exfoliation [9], electron beam lithography [10] and surface passivating agents [11]. As the approach for the synthesis of GQDs, is referred to involve green synthesis, which would enable us a higher degree of control of the particle properties and have an environmental benign potential. Many studies, have proved top down approach, Hydrothermal Flow Synthesis technique to be an appropriate and green synthesized technique for production of Nanomaterials, as it involves continuously mixing streams of supercritical water and water soluble precursor(s) together, leading to the controlled and green manufacture of a wide range of applications [12]. Hence it has made an interest to us to postulate the utilizing the hydrothermal flow synthesis for synthesis of GQDs nanoparticles, using hydrazine hydrate capping agent and reducing agent.

The tropical tree Theobroma cacao, known as cacao or cocoa, belongs to the family Sterculiaceae, order Malvales. Cocoa beans are grown primarily as an intercrop in Andhra pradesh, Tamil nadu, Karnataka, and kerala, as the tree requires about $40-50 \%$ shade. Cocoa was used by ancient peoples as medicinal plants for treating various disorders [13]. The cocoa beans contain a large number of phytochemicals and physiologically active compounds. It is also rich in polyphenols, xanthine and anthocyanins [14]. The consumption of cocoa, which possess high anti-oxidant activity, could be beneficial in decreasing damage caused by 
genotoxic and epigenetic carcinogens and inhibit the complex process leading to cancer. All these desirable biological potentials of the chemical components of cocoa beans motivated the present investigation into its nano-biotechnological potential in green chemistry [13]. In this investigation, we report for the first time the synthesis of graphene quantum dots using cocoa seed extract as a reducing and capping agents, as well as demonstration of its anti-microbial, antioxidant and anticancer activities.

\section{MATERIALS AND METHODS}

\section{A.Collection and processing of sample}

Fresh cocoa seeds were collected and the seeds were then washed, air-dried, then crushed and milled into powder with the aid of electric bender. Cocoa seed extract was obtained following the methods of Lateef et al. [15-17] and later filtered and then centrifuged at $4000 \mathrm{rpm}$ to get the final cocoa seed extract (CSE). Then, the extract was stored at $4^{\circ} \mathrm{C}$ for further use.

\section{B.Green synthesis of CSE-GQDs and characterization}

CSE-GQDs was produced from a reaction mixture containing $1 \mathrm{ml}$ of hydrazine hydrate and $0.1 \mathrm{~g} \mathrm{CSE}$ dissolved in $10 \mathrm{ml}$ of double distilled water and then ultra-sonicated for $30 \mathrm{~min}$. Then, the solution was transferred into a $25 \mathrm{ml}$ teflon lined stainless autoclave. The sealed autoclave was heated to $150-200{ }^{\circ} \mathrm{C}$ in an electric oven and kept for additional 6-10 h. After cooled to room temperature, the product containing water-soluble GQDs was filtered through a $0.22 \mathrm{~mm}$ microporous membrane to remove insoluble carbon product, and further dialyzed in a dialysis bag for 2 days to remove unused small molecules. The purified black GQDs were dried at $80{ }^{\circ} \mathrm{C}$. The formation of CSE-GQDs was confirmed by measuring its absorbance spectrum using UV-visible spectrophotometer. The identity of the biomolecules that took part in the green synthesis was determined by FTIR, while the size, morphology and elemental composition of CSE- GQDs was unraveled by XRD, Transmission electron microscopy (TEM) and SAED pattern [18]

\section{C.Antimicrobial activities of the synthesized CSE-GQDs}

The antibacterial and antifungal property of the synthesized CSE-GQDs was investigated using the agar well diffusion method. Clinical isolates of Staphylococcus aureus, Pseudomonas aeroginosa, Streptococcus mutans, Salmonella sp, Escherichia coli, Microsporum gypseum and Trichophyton $\mathrm{sp}$ obtained from the Department of Microbiology, VIT, Vellore were used as test organisms. Overnight grown cultures were used to seed the plates of Muller-Hinton agar and Sabouraud Dextrose agar medium. The plates were then bored using a cork borer $(7 \mathrm{~mm})$ to create wells. The wells were irrigated with $100 \mu \mathrm{l}$ of different concentrations $(30 \mu 1,60 \mu 1$ and $90 \mu 1)$ of CSE-GQDs prepared by dispersion in sterile distilled water. The plates were thereafter incubated at $37^{\circ} \mathrm{C}$ for $24 \mathrm{~h}$ and $28^{\circ} \mathrm{C}$ for $48 \mathrm{~h}$.
Standard used were Streptomycin and Ketaconazole. At the end of incubation, the plates were examined for the zones of inhibition, which were then measured [19].

\section{D.DPPH free radical assay}

A procedure similar to that reported by Molyneux, 2004 was carried out, where the concentration of DPPH was monitored by UV-Vis absorption spectroscopy at $515 \mathrm{~nm}$. In the presence of antioxidants in the darkness DPPH changes its colour from purple to yellow. Freshly prepared $1 \mathrm{ml}$ of $(100 \mu \mathrm{M})$ methanolic DPPH solution was mixed with $1 \mathrm{ml}$ of various concentrations $(100,200,300,400$ and $500 \mu \mathrm{g} / \mathrm{ml})$ of GQDs and incubated in the dark for $1 \mathrm{hr}$. The radical scavenging activity of each GQDs at different concentrations was evaluated from the absorbance decrease at $515 \mathrm{~nm}$ for GQDs-DPPH mixtures with respect to the absorbance of the control. Ascorbic acid $(5 \mu \mathrm{g} / \mathrm{ml})$ was used as standard. Measurements were replicated three times [18].

DPPH radical scavenging activity $(\%)=\underline{\mathrm{A}}_{\underline{\mathrm{c}}}-\underline{\mathrm{A}}_{\mathrm{GQDs}}-\mathrm{X} 100$

$\mathrm{A}_{\mathrm{c}}$

\section{E.Anticancer activities of the synthesized CSE-GQDs}

\section{Cell culture}

MCF-7 cells were cultured in high glucose Dulbecco's modified Eagle's medium containing 10\% heat -inactivated fetal bovine serum, 100 units $/ \mathrm{ml}$ penicillin, and $100 \mu \mathrm{g} / \mathrm{ml}$ streptomycin at $37^{\circ} \mathrm{C}$ in a $5 \% \mathrm{CO}_{2}$ humidified atmosphere. The medium was changed every two days during the incubation. Cells were made quiescent by starvation after growth to $70-80 \%$ confluence and then treated with experimental reagent [20].

\section{F.Cell viability assay}

Cells $\left(1 \times 10^{5} /\right.$ well $)$ were plated in 24 -well plates and incubated in $37^{\circ} \mathrm{C}$ with $5 \% \mathrm{CO}_{2}$ condition. After the cell reaches the confluence, the various concentrations of the CSE-GQDs were added and incubated for 24hrs. After incubation, the CSE-GQDs was removed from the well and washed with phosphate-buffered saline ( $\mathrm{pH} 7.4) .100 \mu \mathrm{l} /$ well $(5 \mathrm{mg} / \mathrm{ml}) \quad$ of $\quad 0.5 \% \quad 3-(4$, 5-dimethyl-2-thiazolyl)-2,5-diphenyl--tetrazolium bromide (MTT) was added and incubated for 4 hours. After incubation, $1 \mathrm{ml}$ of DMSO was added in all the wells. The absorbance at $570 \mathrm{~nm}$ was measured with UVSpectrophotometer using DMSO as the blank. Measurements were performed and the concentration required for a $50 \%$ inhibition (IC50) was determined graphically. The experiment was carried out in triplicates. The $\%$ cell viability was calculated using the following formula: $\%$ Cell viability $=$ A570 of treated cells / A570 of control cells $\times 100$ Graphs are plotted using the $\%$ of Cell Viability at $\mathrm{Y}$-axis and concentration of the sample in $\mathrm{X}$-axis. Cell control and sample control is included in each assay to compare the full cell viability assessments [20].

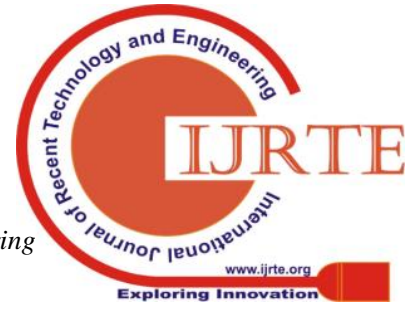




\section{G.CSE-GQDs treatment with green gram seeds}

Green gram (Vigna radiata) seeds of approximately 30 seeds were soaked in distilled water with CSE-GQDs (also referred as control medium or growth medium) and stirred for $3 \mathrm{hrs}$ for hydration. Approximately 10 seeds of the same size were selected and placed about $3 \mathrm{~cm}$ deep in soil and watered every day. The pots were placed at room temperature and $55 \%$ relative humidity. Germination begins after 4 days of sowing and the number of germinated seeds was recorded every 24 hrs [21].

\section{RESULTS AND DISCUSSIONS}

\section{A.Green synthesis of CSE-GQDs and characterization}

The optical properties of the synthesized CSE-GQDs were studied using UV-vis spectroscopy (Fig.1). From the UV-visible spectrum, a distinct absorption peak around 275 $\mathrm{nm}$ was observed. In agreement with these findings, absorption peak around $227 \mathrm{~nm}$ was observed by Jiang et al. [22]. Fig.2. reveals the FTIR spectrum of CSE-GQDs. The transmittance peaks at the spectrum are displayed at 3343.81 , 2973.56, 2952.82, 2595.83, and 1713.31. The peak at 3343.81 corresponds to strong alcoholic $\mathrm{OH}$ stretch and the peak at 2973.56 and 2952.82 corresponds to strong carboxylic acid $\mathrm{OH}$ stretch and weak $-\mathrm{C}-\mathrm{H}$ stretch. The peak at 1713.31 shows strong $\mathrm{C}=\mathrm{O}$ amide stretch. The XRD pattern of CSE-GQDs exhibited peaks at 18.25, 32.42, 33.45, $37.65,42.98,45.87$ which can be assigned the (111), (220), (311), (222), (400), (331) planes of CSE-GQDs (Fig.3). The morphology, composition and structural properties of CSE-GQDs studied using TEM. Figure.4. shows the TEM image of CSE-GQDs which reveals that they are planar nanocrystals. The average size of the resultant GQDs decreases from 12 to $3.4 \mathrm{~nm}$ with increasing scan rates, as verified by their TEM images. Fig.5. shows the SAED pattern with diffraction rings corresponding to the (102), (110), (112), (200), (210) planes of CSE-GQDs. The TEM data is thus in good agreement with XRD.

\section{B.Antimicrobial activities of the synthesized CSE-GQDS}

The antimicrobial activity of CSE- GQDs was determined by well diffusion method. The results indicated that the CSEGQDs showed the greatest antimicrobial activity against the tested organism (Table 1). There are three different concentrations $(30 \mu 1,60 \mu 1$ and $90 \mu 1)$ which were taken to kill the pathogenic microorganisms.

\section{C.Anti-oxidant activities of the synthesized CSE-GQDs}

The antioxidant activity of the CSE- GQDs was evaluated using DPPH scavenging assays. As shown in table 2, a significant difference was observed among the respective values obtained. The DPPH values were increased in a dose dependent manner. The recorded value for the lowest concentration of the CSE- GQDs $(100 \mu \mathrm{g} / \mathrm{ml})$ was $43 \%$ and this value was increased to $84 \%$ when the concentration was increased to $500 \mu \mathrm{g} / \mathrm{ml}$. These results indicated that CSEGQDs possessed a higher scavenging activity. This indicates a strong hydrogen donor behavior as a result of their large amount of functional groups at edge sites for the free electron delocalization and stabilization. Previous reports by Ruiz et al.[23] demonstrated the great potential of antioxidant activity of GQDs. The results showed an remarkable influence of the chemical composition of a series of GQDs on their antioxidant and free radical scavenging activity. The GQD exhibited an extraordinary high antioxidant activity, with inhibition effective concentrations for ROS considerably lower than those of ascorbic acid or other carbon nanomaterials.

\section{Anticancer activities of the synthesized CSE-GQDs}

The cytotoxicity studies showed that the synthesized CSEGQDs exhibited a dose dependent toxicity on human breast cancer (MCF-7) cell lines. It is found that the cell viability is decreasing with increase in the concentration of the CSEGQDs. The $\mathrm{IC}_{50}$ value for MCF-7 cells is found to be $31.2 \mu \mathrm{g} / \mathrm{ml}$ of CSE- GQDs, where a $50 \%$ noticed cell death is observed (Fig 6 and Table 3). However, it is not clear why GQDs do not affect normal cells, though it is a good sign. Previous report by Sui et al [20] also demonstrated that combination of GQDs with cisplastin effectively enhance the cytotoxicity, cell cycle arrest and DNA fragmentation.

\section{E.CSE-GQDs treatment with green gram seeds}

The germination rate of green gram seeds significantly increased after treatment with higher CSE-GQDs. The germination percentage $(\%)$ of green gram seeds was found to be $80 \%$ when treated with CSE-GQDs and untreated showed only $20 \%$ germination. The length of shoot and root were also significantly affected by the untreated seeds rather than the treated one. The plumule and radical length of green gram seeds was represented in Table 4 and Fig.7.

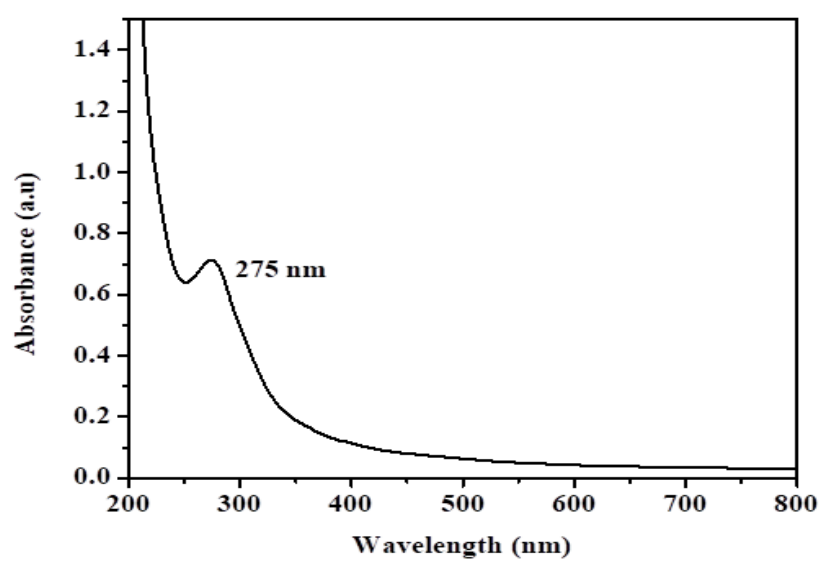

Figure 1 UV-Vis absorption spectrum of cocoa seed extract-grapheme quantum dots (CSE- GQDs)
Published By: Engineering \& Sciences Publication 


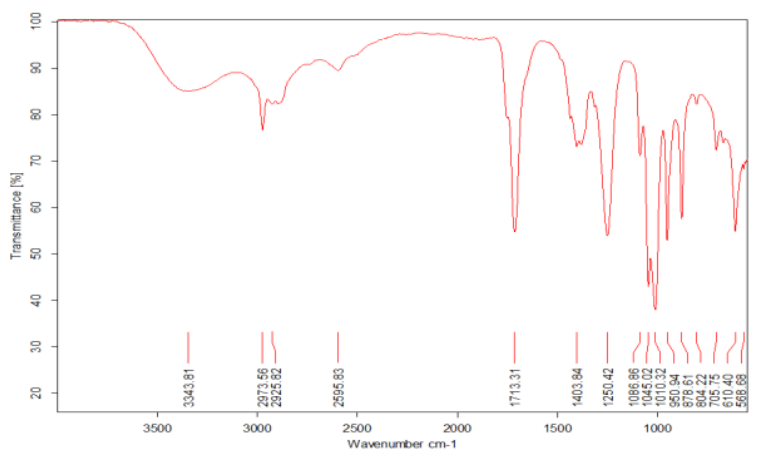

Figure. 2 FT-IR spectrum of cocoa seed extract-grapheme quantum dots (CSE- GQDs)

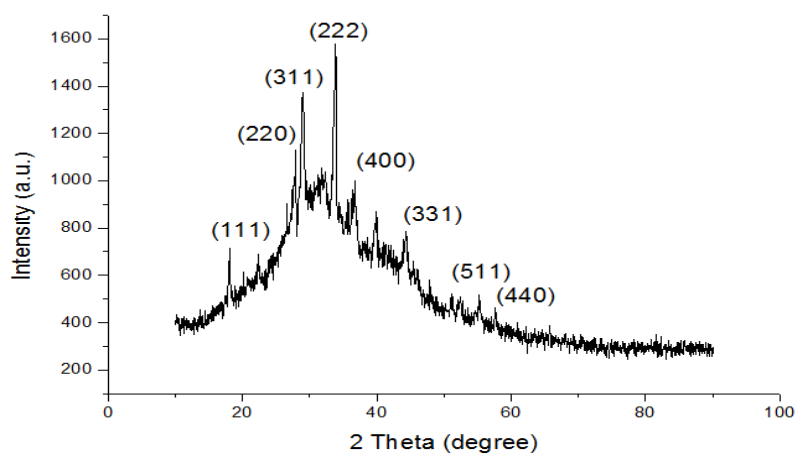

Figure .3 XRD pattern of cocoa seed extract-grapheme quantum dots (CSE- GQDs)

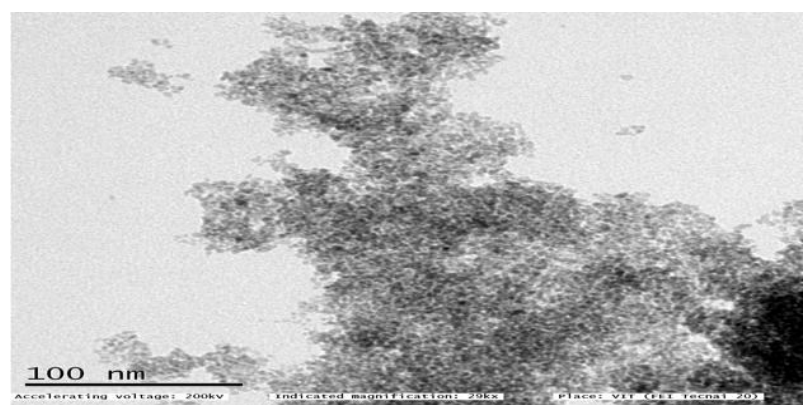

Figure.4 TEM analysis of cocoa seed extract-graphene quantum dots (CSE- GQDs)

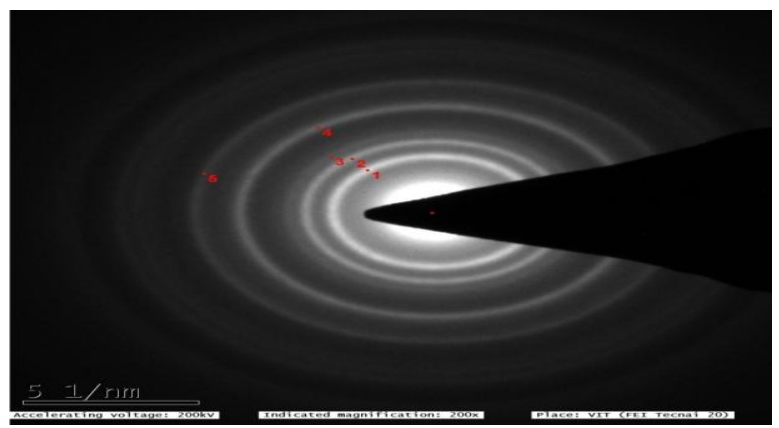

Figure. 5 SAED pattern of cocoa seed extract-grapheme quantum dots (CSE- GQDs)
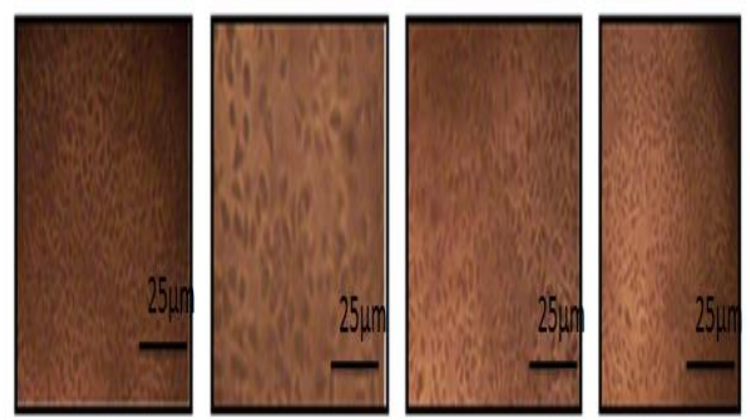

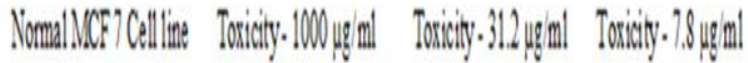

Figure.6 Anticancer activity of cocoa seed extract-grapheme quantum dots (CSE- GQDs) on MCF 7 cell line

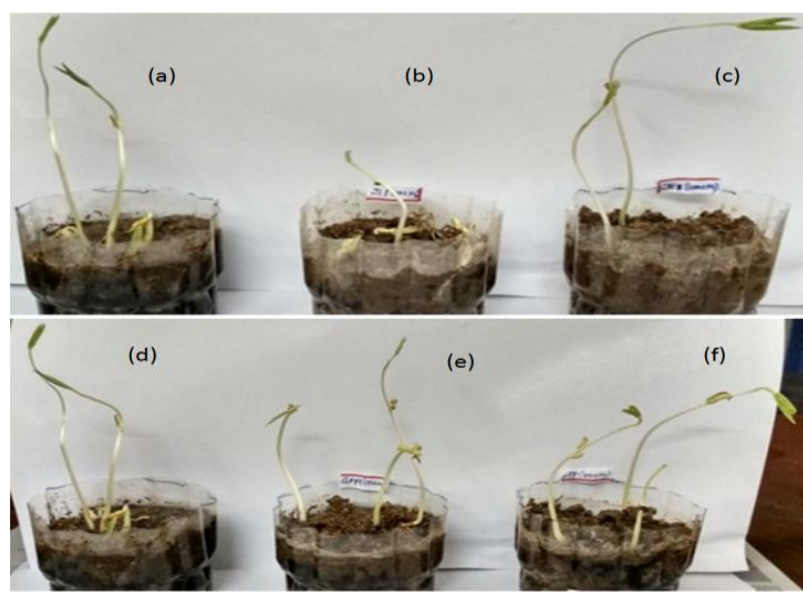

Figure 7. Phytotoxicity study of cocoa seed extract-grapheme quantum dots (CSE- GQDs) (a) Control (b) Untreated seeds (c) Treated seeds (25 $\mu$ l of CSE- GQDs ) (d) Treated seeds (50 $\mu$ l of CSE- GQDs) (e)

Treated seeds (75 $\mu$ l of CSE- GQDs) (f) Treated seeds (100 $\mu$ l of CSE- GQDs)

Table.1 Antimicrobial activities of the synthesized CSEGQDs

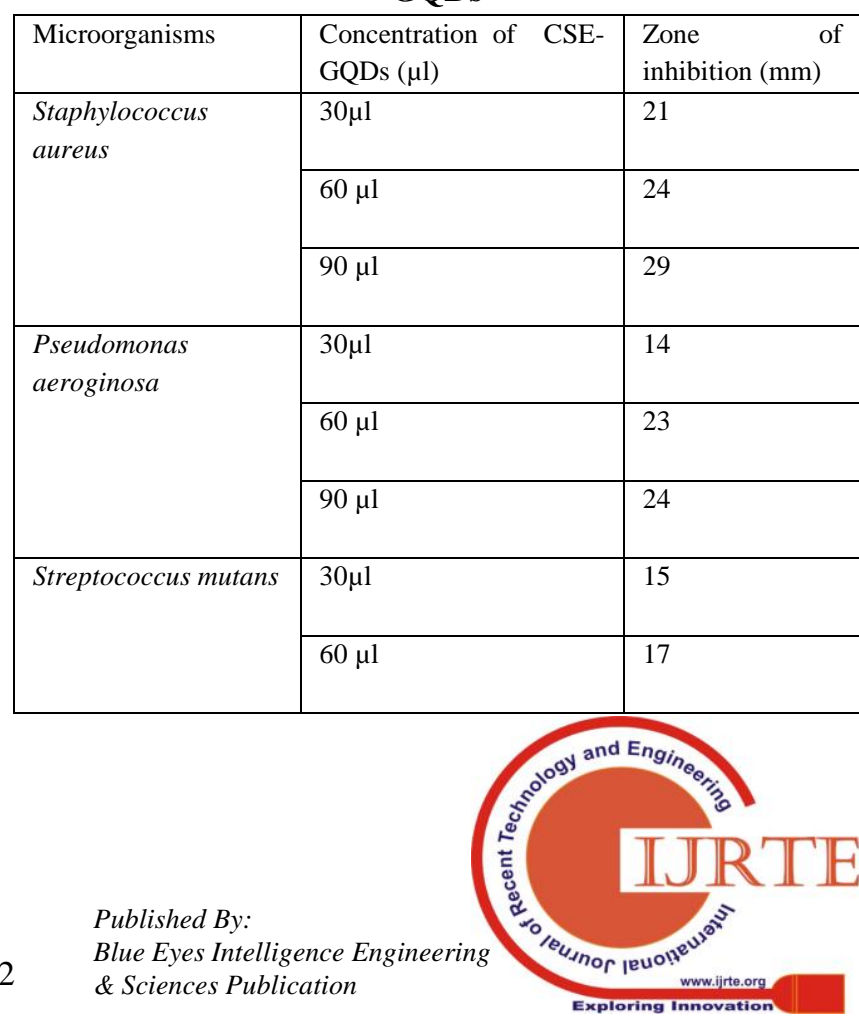




\begin{tabular}{|c|c|c|}
\hline & $90 \mu \mathrm{l}$ & 20 \\
\hline \multirow[t]{3}{*}{ Salmonella sp } & $30 \mu 1$ & 16 \\
\hline & $60 \mu 1$ & 18 \\
\hline & $90 \mu 1$ & 20 \\
\hline \multirow[t]{3}{*}{ Escherichia coli } & $30 \mu 1$ & 21 \\
\hline & $60 \mu 1$ & 22 \\
\hline & $90 \mu 1$ & 28 \\
\hline \multirow{3}{*}{$\begin{array}{l}\text { Microsporum } \\
\text { gypseum }\end{array}$} & $30 \mu 1$ & 11 \\
\hline & $60 \mu 1$ & 15 \\
\hline & $90 \mu \mathrm{l}$ & 17 \\
\hline \multirow[t]{3}{*}{ Trichophyton $\mathrm{sp}$} & $30 \mu 1$ & 13 \\
\hline & $60 \mu 1$ & 16 \\
\hline & $90 \mu \mathrm{l}$ & 19 \\
\hline
\end{tabular}

Table.2 Antioxidant activity

\begin{tabular}{|l|l|}
\hline $\begin{array}{l}\text { Concentration } \\
(\mu \mathrm{g} / \mathrm{ml})\end{array}$ & Test \\
\hline 100 & $43 \pm 0.9$ \\
\hline 200 & $51 \pm 0.8$ \\
\hline 300 & $67 \pm 0.1$ \\
\hline 400 & $79 \pm 0.0$ \\
\hline 500 & $84 \pm 0.6$ \\
\hline
\end{tabular}

Table.3 Anticancer activity of GQDs on MCF 7 cell line

\begin{tabular}{|l|l|l|l|}
\hline $\begin{array}{l}\text { Concentration } \\
(\mu \mathrm{g} / \mathrm{ml})\end{array}$ & Dilutions & $\begin{array}{l}\text { Absorbance } \\
(\mathrm{O} . \mathrm{D})\end{array}$ & Cell viability \\
\hline 1000 & Neat & 0.161 & $17.61 \pm 0.9$ \\
\hline 500 & $1: 1$ & 0.236 & $25.82 \pm 0.6$ \\
\hline 250 & $1: 2$ & 0.286 & $31.29 \pm 0.1$ \\
\hline 125 & $1: 4$ & 0.352 & $38.51 \pm 1.2$ \\
\hline 62.5 & $1: 8$ & 0.403 & $44.09 \pm 0.4$ \\
\hline 31.2 & $1: 16$ & 0.472 & $51.64 \pm 1.6$ \\
\hline 15.6 & $1: 32$ & 0.524 & $57.33 \pm 1.7$ \\
\hline 7.8 & $1: 64$ & 0.597 & $65.31 \pm 0.0$ \\
\hline Cell control & - & 0.914 & $100 \pm 0.0$ \\
\hline
\end{tabular}

Table.4 The germination (\%) of Vigna radiata

\begin{tabular}{|l|l|l|}
\hline Treatments & \multicolumn{2}{|l|}{ Vigna radiata } \\
\cline { 2 - 3 } & Plumule $(\mathrm{cm})$ & Radicle $(\mathrm{cm})$ \\
\hline Control (Water) & $30 \pm 1.4$ & $11 \pm 0.5$ \\
\hline Untreated Seed & $6.8 \pm 0.51$ & $5.4 \pm 2.1$ \\
\hline $\begin{array}{l}\text { Treated Seed (CSE- } \\
\text { GQDs) }\end{array}$ & $17 \pm 0.52$ & $8.4 \pm 0.8$ \\
\hline
\end{tabular}

\section{CONCLUSION}

The biosynthesized GQDs have been characterized by UV-Vis, FTIR, XRD and TEM. The CSE-GQDs showed excellent anti-microbial, anti-oxidant and anti-cancer activities. Also, we have demonstrated the use of GQDs as plant growth regulator in green gram seeds. It has been observed that the growth rates of plant were increased substantially in the presence of GQDs. The use of non-toxic GQDs in plant growth might plays an important role in the area of agriculture for enhanced production.

\section{REFERENCES}

1. S. Mukherjee and C. R. Patra. Future Sci. OA 3(3), (2017) pp. 203

2. Lateef, M. A. Azeez, T. B. Asafa, T. A. Yekeen, A. Akinboro, I.C. Oladipo, L. Azeez. S. A. Ojo, E. B. Gueguim-Kana, L. S. Beukes. J Nanostruct Chem 6 (2), (2016) pp. 159-169

3. S. Ramachandran, M. Sathishkumar, N. K. Kothurkar, R Senthilkumar. Materials Science and Engineering 310 (2018) 012139.

4. Z. Xue, H. GAO, X. Li. DYES AND PIGMENTS. 156 (2018) PP. 379-385.

5. X. YAN, X. CUI, L. S. LI. JOURNAL OF THE AMERICAN CHEMICAL SOCIETY 132 (17), (2010): 5944-5945.

6. M. L. Mueller, X. YAN, B. Dragnea, L. S. Li. NANO LetTers 11 (1) (2010): 56-60

7. R. Liu, D. Wu, X. Feng, K. Mullen. Journal of the American Chemical Society 133(39), (2011) pp. 15221-15223.

8. D. Pan, J. Zhang, Z. Li, M. Wu. Advanced materials 22 (6), (2010) pp 734-738.

9. D. B. Shinde, V. K. Pillai. Chemistry-A European Journal 18 (39), (2012) pp. 12522-12528.

10. L. A. Ponomarenko, F. Schedin, M.I. Katsnelson, R. Yang, E. W. Hill, K. S. Novoselov, A. K. Geim. Science 320 (5874), (2008) pp. 356-358.

11. J. Shen, Y. Zhu, X. Yang, J. Zong, J. Zhang, C. Li. New Journal of Chemistry 36 (1), (2012), 97-101.

12. S. Kellici, J. Acord, N. P. Power, D. J. Morgan, P. Coppo, T. Heil, B. Saha. RSC Advances 7 (24), (2017) pp. 14716-14720.

13. Baharum Z, A. M. Akim, T. Y. Y. Hin, R. A. Hamid, R. Kasran. Trop Life Sci Res. 2016, 27(1): 21-42.

14. M. A. Azeez, A. Lateef, T. B. Asafa, T. A. Yekeen, A. Akinboro, I. C. Oladipo, E. B. Gueguim-Kana, L. S. Beukes. J Clust Sci (2017) 28, 149-164.

15. Lateef, M. A. Azeez, T. B. Asafa, T. A. Yekeen, A. Akinboro, I. C. Oladipo, L. Azeez, S. E. Ajibade, S. A. Ojo, E. B. Gueguim-Kana, and L. S. Beukes, J. Taibah Univ. Sci. (2016), 10, 551

16. Lateef, M. A. Azeez, T. B. Asafa, T. A. Yekeen, A. Akinboro, I. C. Oladipo, L. Azeez, S. E. Ajibade, S. A. Ojo, E. B. Gueguim-Kana, and L. S. Beukes. J. Nanostruct. Chem. (2016), 6, 159.

17. Lateef, M. A. Azeez, T. B. Asafa, T. A. Yekeen, A. Akinboro, I. C. Oladipo, F. E. Ajetomobi, E. B. Gueguim-Kana, and L. S. Beukes. Bionanoscience. (2015), 5, 196.

18. L. A. Avinash Chunduri, Aditya Kurdekar, Sandeep Patnaik, B. Vishnu Dev, Tanu Mimani Rattan, and Venkataramaniah Kamisetti. Materials Focus. (2016), 5, pp. 55-61.

19. 19.L. Hui, J. Huang, G. Chen, Y. Zhu and L. Yang. ACS Appl. Mater. Interfaces (2016), 8, 20-25

20. X. Sui, Luo C. C. Wang, F. Zhang, J. Zhang, S. Guo. Nanomedicine: Nanotechnology, Biology, and Medicine (2016) 12 (7), pp. 1997-2006

21. D. Tang, J. Liu, X. Yan, L. Kang. Graphene oxide derived graphene quantum dots with different photoluminescence properties and peroxidase-like catalytic activity. RSC Advances, (2016), 6(56), pp 50609-50617.

22. D. Jiang, Y. Chen, N. Li, W. Li, Z. Wang, J. Zhu H. Zhang, B. Liu, S. Xu. PLoS ONE. (2015), 10(12), pp. e0144906.

23. Ruiz, L. Yate, I. García, G. Cabanero, and H. J. Grande. Carbon, (2017) 116, pp.366-374. 